\title{
Assessment of Urinary Netrin-1 as a Marker for Progression of Acute Kidney Injury in Critically Ill Patients: Prospective Cohort Study
}

El Sharkawy $A^{1^{*}}$, El Wakil $\mathbf{H}^{1}$, Naga $\mathbf{Y}^{1}$ and Younan $\mathrm{D}^{2}$

${ }^{1}$ Department of Internal Medicine (Nephrology Unit), Faculty of Medicine, Alexandria University, Alexandria, Egypt

${ }^{2}$ Department of Clinical and Chemical Pathology, Faculty of Medicine, Alexandria University, Alexandria, Egypt

"Corresponding author: Adham El Sharkawy, Department of Internal Medicine (Nephrology Unit), Faculty of Medicine, Alexandria University, Alexandria, Egypt, Tel: +20 3 5921675; E-mail: dr.adham85@gmail.com

Received Date: Jan 24, 2018; Accepted Date: Feb 20, 2018; Published Date: March 10, 2018

Copyright: (c) 2018 El Sharkawy A, et al. This is an open-access article distributed under the terms of the Creative Commons Attribution License, which permits unrestricted use, distribution and reproduction in any medium, provided the original author and source are credited.

\begin{abstract}
Background and objective: This study aimed to identify risk factors for progression of AKI in critically ill adult patients in the medical ICU in Alexandria main University Hospitals and to assess urinary netrin-1 as a marker for progression of $\mathrm{AKI}$.

Design, setting, participants and measurements: The study included $80 \mathrm{AKI}$ patients who were followed during their ICU stay for primary outcome (progression to severe AKI; KDIGO stage 2 or 3 ) and secondary outcomes (need for RRT, ICU mortality, length of ICU stay and SCr at the time of discharge from the ICU). All participants were subjected to history taking, full clinical examination and laboratory (routine and specific) investigations. Urine samples were collected for all patients at the time of ICU admission and urinary netrin-1 was measured.

Result: Almost one third (33.75\%) of the study patients were identified as progressors. Progression was significantly more common among patients with history of CKD $(p<0.001)$, hypotensive patients $(p=0.002)$, septic patients $(p=0.041)$, those who needed RRT $(p<0.001)$ and those who died $(p=0.003)$. Progressors had lower MBP and serum albumin level ( $p=0.007,0.008$, respectively). They had higher APACHE II score and longer ICU stay ( $p=0.037,0.020$, respectively). They also had higher basal blood urea, basal $\mathrm{SCr}$ and $\mathrm{SCr}$ levels at the time of presentation and discharge ( $p<0.001$ for all). The results were similar between progressors and non-progressors, those who received RRT and those who did not and survivors and non-survivors as regards urinary netrin-1 levels. Results of the multivariate analysis revealed that CVD, hypotension and higher basal blood urea level were independent risk factors for AKI progression.
\end{abstract}

Conclusion: The results of this study suggest that history of CKD, hypotension and sepsis are associated with progression of $\mathrm{AKI}$ in critically ill patients and that urinary netrin-1 has no significant value as a predictor of $\mathrm{AKI}$ progression, need for RRT or ICU mortality.

Keywords: AKI novel biomarkers; ICU mortality; Hypotension; Acute kidney injury; Critically ill patient

Abbreviations: CKD: Chronic Kidney Disease; MBP: Mean Blood Pressure; HR: Heart Rate; RR: Respiratory Rate; UOP: Urine Output; SCr: Serum Creatinine; ICU: Intensive Care Unit; APACHE: Acute Physiology and Chronic Health Evaluation; SOFA: Sequential Organ Failure Assessment; RRT: Renal Replacement Therapy; SIRS: Systemic Inflammatory Response Syndrome; AKI: Acute Kidney Injury; HTN: Hypertension; B: Regression coefficient; OR: Odds Ratio; CI: Confidence Interval

\section{Introduction}

AKI is a clinical syndrome characterized by a rapid decrease in renal excretory function, with the accumulation of urea, creatinine and other nitrogenous waste product [1]. While being generally uncommon in the community-dwelling population, AKI is more common in hospitalized individuals with a reported incidence ranging from $2-20 \%$ increasing up to $20-60 \%$ in critically ill patients in whom it is associated with adverse outcomes including increased length of ICU and hospital stay, development of CKD and increased short and long term mortality risk [2].

Multiple risk factors for the development of AKI have been described in critically ill patients. However, the risk for AKI represents the interaction between susceptibility (i.e. features intrinsic to the patient) and exposure (i.e. the causative factor or factors) [3]. Causes of AKI are frequently categorized as pre-renal, intrinsic renal and postrenal, reflecting the overlapping pathologic mechanisms underlying AKI [4].

In the critically ill, sepsis is the major cause of AKI, accounting for nearly $50 \%$ of cases [5]. Many causes of AKI in ICU patients likely represent multifactorial etiologies [4]. AKI is potentially preventable with the fundamental principle of prevention being treatment of the cause or trigger and no specific drug-based intervention has been shown to be protective. Clinically, many patients are asymptomatic and present only with an increase in serum creatinine ( $\mathrm{SCr}$ ) or blood urea or both detected by laboratory tests that are routinely obtained among hospitalized patients [6].

SCr is a poor marker of AKI because patients are not in a steady state and changes in SCr lag behind decrements in renal function [7]. 
Accordingly, identification of biomarkers with the ability to detect early renal injury before histological or functional changes develop would be desirable [8].

Recently, several candidate biomarkers of AKI have been identified including netrin-1 which has been shown to be excreted in urine as early as $1 \mathrm{hr}$ after injury and reach a dramatic 30-40 fold increase by 3 hrs and a peak by 6 hrs after the insult [9].

\section{Materials and Methods}

\section{Study design and participants}

We conducted a prospective cohort study in two medical ICUs in Alexandria Teaching Hospitals. The study included 80 adult AKI patients ( $\geq 18$ years) classified by the KDIGO criteria of AKI who were critically ill, admitted to the medical ICU after June $1^{\text {st }}, 2016$. We excluded patients $<18$ years of age, those with a history of chronic kidney disease $(\mathrm{CKD})$ stage 5 , renal transplant recipients, patients with any surgical interference and those with missing data. We followed participants from the ICU admission date until the earliest of discharge, death or transfer to another unit.

\section{Data collection}

We collected information on the dates of admission and discharge from the ICU, demographics, history of co-morbid conditions (underlying $\mathrm{CKD}$, diabetes mellitus (DM), hypertension (HTN), cardiovascular disease (CVD), stroke, obesity, liver disease, and malignancy) and underlying risk factors including sepsis, hypotension and use of nephrotoxic agents (as contrast material or nephrotoxic antibiotics). After ICU admission, patients were diagnosed as AKI or not based on KDIGO classification [10]. AKI was defined as an increase in SCr by $\geq 0.3 \mathrm{mg} / \mathrm{dl}$ within $48 \mathrm{hrs}$, or increase in SCr to $\geq 1.5$ times baseline; which is known or presumed to have occurred within the prior 7 days, or urine volume $<0.5 \mathrm{ml} / \mathrm{kg} / \mathrm{h}$ for $6 \mathrm{hrs}$. Baseline $\mathrm{SCr}$ was defined as the minimum among the outpatient values measured within 6 months before hospital admission or the inpatient value before ICU admission. For a patient with no SCr measurement within 6 months before ICU admission, the baseline was defined as the minimum among the last values before hospital discharge.

Sepsis was diagnosed based on Sepsis Definition Conference Criteria [11]. Severity of illness was assessed by APACHE II and SOFA scores, which were calculated based on the worst variables recorded during the first $24 \mathrm{hrs}$ after ICU admission to evaluate patient status $[12,13]$. All patients were followed during their ICU stay for primary outcome which was progression to severe AKI (KDIGO stage 2 or 3 ) and secondary outcomes which included the need for RRT, ICU mortality, length of ICU stay and SCr at the time of discharge from the ICU. Laboratory data included repeated measures of SCr, urea, electrolytes, liver enzymes, albumin, bilirubin, coagulation profile, complete blood count and arterial blood gases. Urinary netrin-1 was assessed for all patients at the time of admission by ELISA [14]. Urine samples were collected for all patients at the time of ICU admission and urinary netrin- 1 was measured.

\section{Statistical analysis}

Data were collected and coded using the Statistical Package for Social Sciences; SPSS version 24 (SPSS Inc, Chicago, IL). Qualitative variables were expressed as number and percentage. Association between categorical variables was tested using Chi-square $\left(\chi^{2}\right)$ test. Quantitative variables were expressed as minimum and maximum as well as mean and standard deviation (SD), also exact tests such as student t-test and analytical test of variance (ANOVA test) were applied. Non-normally distributed quantitative data were analyzed using non-parametric tests as Mann Whitney test and Kruskal Wallis test. Spearman coefficient was used to analyze the correlation between the different parameters. Logistic regression analysis for risk factors of progression of AKI was performed using forced entry method. Model fit was assessed using Hosmer-Lemeshow test. Statistical significance was considered at $\mathrm{p} \leq 0.05$.

\section{Result}

\section{Patient characteristics}

Table 1 summarizes the baseline characteristics of the study cohort. The mean age of the study participants $(n=80)$ was $56.54 \pm 13.67$ years, $46.25 \%$ were males, $30 \%$ had pre-existing CKD, $41.25 \%$ were diabetics, $45 \%$ were hypertensive, $40 \%$ had cardiovascular disease and $42.5 \%$ had liver disease. Underlying risk factors included hypotension (46.25\%), sepsis (71.25\%) and use of nephrotoxic agents (12.5\%).

Disease severity was assessed by APACHE II score (mean: $18.81 \pm$ 7.26) and SOFA score (mean: $8.84 \pm 3.51$ ).

\begin{tabular}{|c|c|}
\hline Baseline characteristics & Studied cases $(n=80)$ \\
\hline \multicolumn{2}{|l|}{ Demographics } \\
\hline Age (Years), Mean \pm SD & $56.54 \pm 13.67$ \\
\hline Gender (Male), No. (\%) & $37(46.25)$ \\
\hline Residence (Urban), No. (\%) & $60(75)$ \\
\hline \multicolumn{2}{|l|}{ Co-morbidities, No. (\%) } \\
\hline Pre-existing CKD & $24(30)$ \\
\hline Diabetes mellitus & $33(41.25)$ \\
\hline Hypertension & $45(56.25)$ \\
\hline Cardiovascular disease & $32(40)$ \\
\hline Obesity & $31(38.75)$ \\
\hline Liver disease & $34(42.5)$ \\
\hline Malignancy & $9(11.25)$ \\
\hline \multicolumn{2}{|l|}{ Risk factors, No. (\%) } \\
\hline Hypotension & $37(46.25)$ \\
\hline Sepsis* & $57(71.25)$ \\
\hline Nephrotoxic agents & $10(12.5)$ \\
\hline \multicolumn{2}{|l|}{ Physical signs, Mean \pm SD } \\
\hline $\mathrm{MBP}(\mathrm{mmHg})$ & $74.88 \pm 23.18$ \\
\hline Temperature $\left({ }^{\circ} \mathrm{C}\right)$ & $37.1 \pm 0.28$ \\
\hline $\mathrm{HR}$ (Beats/min) & $88.68 \pm 21.6$ \\
\hline RR (Breaths/min) & $22.05 \pm 7.36$ \\
\hline
\end{tabular}


Citation: El Sharkawy A, El Wakil H, Naga Y, Younan D (2018) Assessment of Urinary Netrin-1 as a Marker for Progression of Acute Kidney Injury in Critically III Patients: Prospective Cohort Study. J Kidney 4: 164. doi:10.4172/2472-1220.1000164

Page 3 of 7

\begin{tabular}{|l|l|}
\hline UOP (ml/h) & $91.44 \pm 86.67$ \\
\hline Laboratory data, Mean \pm SD \\
\hline Basal blood urea (mg/dl) & $73.19 \pm 23.39$ \\
\hline Basal SCr (mg/dl) & $1.55 \pm 0.86$ \\
\hline SCr on ICU admission (mg/dl) & $3.05 \pm 1.78$ \\
\hline SCr at discharge (mg/dl) & $2.17 \pm 1.32$ \\
\hline Urinary netrin-1 (pg/ml) & $650.474 \pm 167.774$ \\
\hline Disease severity, Mean \pm SD \\
\hline Glasgow coma scale & $12.29 \pm 2.46$ \\
\hline APACHE Il score & $18.81 \pm 7.26$ \\
\hline SOFA score & $8.84 \pm 3.51$ \\
\hline Patient outcomes, No. (\%) \\
\hline Progression (progressors) & $27(33.75)$ \\
\hline RRT (received RRT) & $32(40)$ \\
\hline ICU mortality (non-survivors) & $44(55)$ \\
\hline $\begin{array}{l}\text { *Sepsis refers to any stage including Systemic Inflammatory Response } \\
\text { Syndrome (SIRS), sepsis, severe sepsis and septic shock. }\end{array}$ \\
\hline \multicolumn{2}{|l}{} \\
\hline
\end{tabular}

Table 1: Baseline characteristics of the study cohort.

Figure 1 shows distribution of the studied cases according to the different outcomes of each AKI stage.

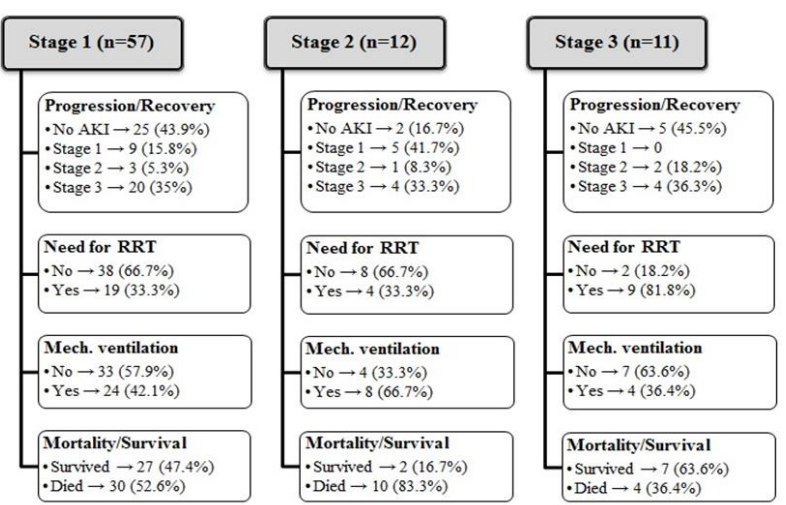

Figure 1: Distribution of the studied cases according to the different outcomes of each AKI stage.

Progression refers to worsening of AKI by at least one KDIGO stage or initiation of Renal Replacement Therapy. No AKI refers to renal recovery which is considered when the last available creatinine fell within $0.3 \mathrm{mg} / \mathrm{dl}$ or $50 \%$ of the baseline value, without requirements for Renal Replacement Therapy.

\section{Disease progression}

Almost one third $(33.75 \%)$ of the study patients were identified as progressors. Progression was significantly more common among patients who were known to have preexisting CKD $(\mathrm{p}<0.001)$, hypotensive patients $(\mathrm{p}=0.002)$, patients who needed RRT $(\mathrm{p}<0.001)$ and patients who died $(\mathrm{p}=0.003)$. Also, the distribution was significantly different between the two groups as regards the AKI stage at the time of presentation $(\mathrm{p}=0.038)$ and the stage of sepsis with progression being more common among those with septic shock $(\mathrm{p}=0.041)$ (Table 2).

Progressors had significantly lower mean BP $(\mathrm{p}=0.007)$, lower serum albumin level $(\mathrm{p}=0.008)$, higher serum $\mathrm{PO}_{4}$ level $(\mathrm{p}=0.006)$, higher basal blood urea level $(\mathrm{p}<0.001)$, higher basal SCr level $(\mathrm{p}<0.001)$, higher level of SCr at the time of presentation $(\mathrm{p}<0.001)$, higher level of SCr at the time of discharge $(\mathrm{p}<0.001)$, higher APACHE II score $(\mathrm{p}=0.037)$ and longer ICU stay $(\mathrm{p}=0.020)$ (Table S1).

\begin{tabular}{|c|c|c|c|c|c|}
\hline \multirow{2}{*}{ Variables } & \multicolumn{2}{|c|}{$\begin{array}{l}\text { Non-progressors } \\
(n=53)\end{array}$} & \multicolumn{2}{|c|}{ Progressors $(n=27)$} & \multirow[t]{2}{*}{$\mathbf{P}$} \\
\hline & No. & $\%$ & No. & $\%$ & \\
\hline \multicolumn{6}{|l|}{ CKD } \\
\hline No CKD & 47 & 88.7 & 9 & 33.3 & \multirow{2}{*}{$<0.001$} \\
\hline known to be CKD & 6 & 11.3 & 18 & 66.7 & \\
\hline \multicolumn{6}{|l|}{ Hypotension } \\
\hline Not hypotensive & 35 & 66 & 8 & 29.6 & \multirow{2}{*}{0.002} \\
\hline Hypotensive & 18 & 34 & 19 & 70.4 & \\
\hline \multicolumn{6}{|l|}{ Stage of Sepsis } \\
\hline No sepsis & 19 & 35.85 & 4 & 14.81 & \multirow{5}{*}{0.041} \\
\hline SIRS & 6 & 11.32 & 0 & 0 & \\
\hline Sepsis & 5 & 9.43 & 7 & 25.93 & \\
\hline Severe sepsis & 7 & 13.21 & 5 & 18.52 & \\
\hline Septic shock & 16 & 30.19 & 11 & 40.74 & \\
\hline \multicolumn{6}{|l|}{$\begin{array}{l}\text { AKI Stage at } \\
\text { Presentation }\end{array}$} \\
\hline Stage 1 & 35 & 66 & 22 & 81.5 & \multirow{3}{*}{0.038} \\
\hline Stage 2 & 7 & 13.2 & 5 & 18.5 & \\
\hline Stage 3 & 11 & 20.8 & 0 & 0 & \\
\hline \multicolumn{6}{|l|}{ Need for RRT } \\
\hline No & 44 & 83 & 4 & 14.8 & \multirow{2}{*}{$<0.001$} \\
\hline Yes & 9 & 17 & 23 & 85.2 & \\
\hline \multicolumn{6}{|l|}{ ICU Mortality } \\
\hline Survivors & 30 & 56.6 & 6 & 22.2 & \multirow{2}{*}{0.003} \\
\hline Non-survivors & 23 & 43.4 & 21 & 77.8 & \\
\hline
\end{tabular}

Table 2: Comparison between progressors and non-progressors.

\section{Need for RRT}

$40 \%$ of the study patients received RRT. There was a significantly higher need for RRT among patients who were known to have 
Citation: El Sharkawy A, El Wakil H, Naga Y, Younan D (2018) Assessment of Urinary Netrin-1 as a Marker for Progression of Acute Kidney Injury in Critically III Patients: Prospective Cohort Study. J Kidney 4: 164. doi:10.4172/2472-1220.1000164

Page 4 of 7

preexisting CKD, hypertensive patients, those with liver disease and disease progression $(\mathrm{p}<0.001, \mathrm{p}=0.021, \mathrm{p}=0.042, \mathrm{p}<0.001$, respectively). Also, the distribution was significantly different between the two groups as regards the AKI stage at presentation ( $\mathrm{p}=0.010)$ (Table 3 ).

Patients who received RRT had significantly lower heart rate and hemoglobin level $(\mathrm{p}=0.018,0.012$, respectively). They had higher APACHE II and SOFA scores $(\mathrm{p}<0.001, \mathrm{p}=0.008$, respectively). They also had higher serum PO4, basal blood urea, basal SCr and SCr levels at the time of presentation and discharge ( $\mathrm{p}<0.001$ for all) (Table S2).

\begin{tabular}{|c|c|c|c|c|c|}
\hline \multirow[t]{2}{*}{ Variables } & \multicolumn{2}{|c|}{ No RRT $(n=48)$} & \multicolumn{2}{|c|}{ RRT (n=32) } & \multirow[t]{2}{*}{$\mathbf{P}$} \\
\hline & No. & $\%$ & No. & $\%$ & \\
\hline \multicolumn{6}{|l|}{ CKD } \\
\hline No CKD & 42 & 87.5 & 14 & 43.75 & \multirow{2}{*}{$<0.001$} \\
\hline known to be CKD & 6 & 12.5 & 18 & 56.25 & \\
\hline \multicolumn{6}{|l|}{ HTN } \\
\hline Not hypertensive & 26 & 54.2 & 9 & 28.1 & \multirow{2}{*}{0.021} \\
\hline Hypertensive & 22 & 45.8 & 23 & 71.9 & \\
\hline \multicolumn{6}{|l|}{ Liver Disease } \\
\hline Absent & 32 & 66.7 & 14 & 43.75 & \multirow{2}{*}{0.042} \\
\hline Present & 16 & 33.3 & 18 & 56.25 & \\
\hline \multicolumn{6}{|c|}{$\begin{array}{l}\text { AKI Stage at } \\
\text { Presentation }\end{array}$} \\
\hline Stage 1 & 38 & 79.2 & 19 & 59.4 & \multirow{3}{*}{0.010} \\
\hline Stage 2 & 8 & 16.7 & 4 & 12.5 & \\
\hline Stage 3 & 2 & 4.1 & 9 & 28.1 & \\
\hline \multicolumn{6}{|l|}{ Progression } \\
\hline Non-progressors & 44 & 91.7 & 9 & 28.1 & \multirow{2}{*}{$<0.001$} \\
\hline Progressors & 4 & 8.3 & 23 & 71.9 & \\
\hline
\end{tabular}

Table 3: Comparison between RRT and no RRT.

\section{ICU mortality}

More than half (55\%) of the study patients died. Mortality was significantly more common among patients known to have CKD, those with liver disease and disease progression $(p<0.001, p=0.016,0.003$, respectively). Also, the distribution was significantly different between the two groups as regards the stage of sepsis with mortality being more common in patients with septic shock $(\mathrm{p}=0.010)$ (Table 4$)$.

Non-survivors had significantly lower platelet count and serum albumin level $(\mathrm{p}=0.008,0.004$, respectively). They had higher serum AST and total bilirubin levels ( $\mathrm{p}=0.008,0.006$, respectively), higher PT, PTT and INR ( $<<0.001, p=0.006, p<0.001$, respectively) and higher APACHE II and SOFA scores $(p=0.002, p<0.001$, respectively). They also had higher blood lactate, basal blood urea, basal SCr and $\mathrm{SCr}$ levels at the time of presentation and discharge $(\mathrm{p}<0.001$ for all) (Table S3).

\section{Length of ICU stay}

It was longer among hypertensive patients and progressors $(\mathrm{p}=0.046,0.020$, respectively) (Table $\mathrm{S} 4)$. There were statistically significant negative correlations with serum AST, ALT and Ca levels $(\mathrm{p}=0.033,0.001,0.002$, respectively) (Table $\mathrm{S} 5)$.

\section{SCr at the time of discharge}

The level was higher among patients with liver disease $(\mathrm{p}=0.008)$, patients who were known to have preexisting $\mathrm{CKD}$, progressors, those who received RRT and non-survivors ( $\mathrm{p}<0.001$ for all). Also, the level was significantly different as regards the different stages of sepsis being higher among patients with septic shock $(\mathrm{p}=0.007)$ (Table S4).

\begin{tabular}{|c|c|c|c|c|c|}
\hline \multirow[t]{2}{*}{ Variables } & \multicolumn{2}{|c|}{ Survivors $(n=36)$} & \multicolumn{2}{|c|}{$\begin{array}{l}\text { Non-survivors } \\
(n=44)\end{array}$} & \multirow[t]{2}{*}{$\mathbf{P}$} \\
\hline & No. & $\%$ & No. & $\%$ & \\
\hline \multicolumn{6}{|l|}{ CKD } \\
\hline No CKD & 35 & 97.2 & 21 & 47.7 & \multirow{2}{*}{$<0.001$} \\
\hline known to be $C K D$ & 1 & 2.8 & 23 & 52.3 & \\
\hline \multicolumn{6}{|l|}{ Liver Disease } \\
\hline Absent & 26 & 72.2 & 20 & 45.5 & \multirow{2}{*}{0.016} \\
\hline Present & 10 & 27.8 & 24 & 54.5 & \\
\hline \multicolumn{6}{|l|}{ Stage of Sepsis } \\
\hline No sepsis & 13 & 36.1 & 10 & 22.7 & \multirow{5}{*}{0.010} \\
\hline SIRS & 6 & 16.7 & 0 & 0 & \\
\hline Sepsis & 6 & 16.7 & 6 & 13.6 & \\
\hline Severe sepsis & 4 & 11.1 & 8 & 18.2 & \\
\hline Septic shock & 7 & 19.4 & 20 & 45.5 & \\
\hline \multicolumn{6}{|l|}{ Progression } \\
\hline Non-progressors & 30 & 83.3 & 23 & 52.3 & \multirow{2}{*}{0.003} \\
\hline Progressors & 6 & 16.7 & 21 & 47.7 & \\
\hline
\end{tabular}

Table 4: Comparison between survivors and non-survivors.

There were statistically significant positive correlations between $\mathrm{SCr}$ at discharge and age $(\mathrm{p}=0.021)$, blood lactate level $(\mathrm{p}=0.001)$, PT $(\mathrm{p}=0.006)$, PTT $(\mathrm{p}=0.006)$, INR $(\mathrm{p}=0.005)$ and serum $\mathrm{PO}_{4}$ level $(p=0.029)$. Also, it was positively correlated with basal blood urea, basal SCr and SCr level at the time of presentation and APACHE II and SOFA scores $(\mathrm{p}<0.001$ for all).

On the other hand, there were statistically significant negative correlations with hemoglobin level, platelet count, serum albumin and Na levels ( $p=0.003,0.016,0.001,0.021$, respectively) (Table S5).

\section{Urinary netrin-1}

Regarding urinary netrin-1, there was no statistically significant difference between progressors and non-progressors, those who received RRT and those who did not and survivors and non-survivors. Except for a significant positive correlation with serum total bilirubin 
Citation: El Sharkawy A, El Wakil H, Naga Y, Younan D (2018) Assessment of Urinary Netrin-1 as a Marker for Progression of Acute Kidney Injury in Critically III Patients: Prospective Cohort Study. J Kidney 4: 164. doi:10.4172/2472-1220.1000164

Page 5 of 7

level ( $p=0.006$ ), no statistically significant correlations or differences were found with the other parameters.

ROC curves were constructed to assess the usefulness of urinary netrin-1 in the prediction of disease progression, the need for RRT and ICU mortality revealing that it had no significant value as a predictor of any of them (Figures 2-4).

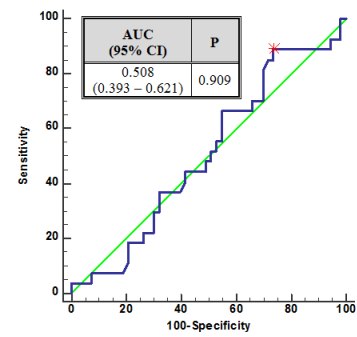

Figure 2: ROC curve for urinary Netrin-1 to predict disease progression.

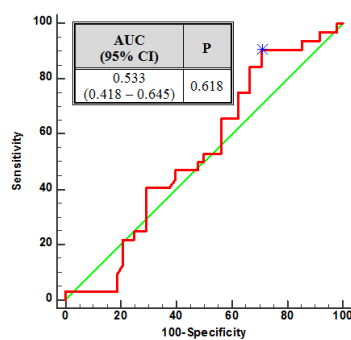

Figure 3: ROC curve for urinary Netrin-1 to predict the need for RRT.

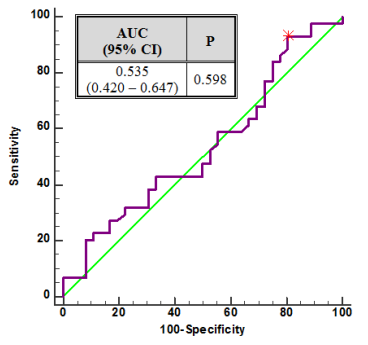

Figure 4: ROC curve for urinary Netrin-1 to predict ICU mortality.

\section{Multivariate analysis}

We conducted multivariable logistic regression analysis to assess the risk factors for progression of AKI. The variables considered for inclusion in the model were based on clinical judgment [15-18]. They included demographic data (age and gender), chronic co-morbidities (CKD, DM, HTN, CVD and chronic liver disease), acute events (hypotension and sepsis or septic shock) and laboratory markers (basal levels of blood urea and SCr and level of SCr on admission). We found that CVD, hypotension and higher basal blood urea level were independent risk factors for AKI progression, while we failed to prove the significance of other variables in our model (Table 5). Ideally, a larger multicenter sample is needed to produce a more robust model.

\begin{tabular}{|c|c|c|c|c|}
\hline Independent Variables & B & $\mathbf{P}$ & OR & $95 \% \mathrm{Cl}$ \\
\hline \multicolumn{5}{|l|}{ Demographics } \\
\hline Age (in years) & -0.072 & 0.073 & 0.931 & 0.861 \\
\hline Sex (female vs. male) & -0.902 & 0.307 & 0.406 & 0.072 \\
\hline \multicolumn{5}{|l|}{ Co-morbid Conditions } \\
\hline $\begin{array}{l}\text { Chronic Kidney Disease (yes vs. } \\
\text { no) }\end{array}$ & -0.803 & 0.563 & 0.448 & 0.029 \\
\hline Diabetes Mellitus (yes vs. no) & -0.342 & 0.733 & 0.711 & 0.1 \\
\hline Hypertension (yes vs. no) & -1.382 & 0.133 & 0.251 & 0.041 \\
\hline $\begin{array}{l}\text { Cardiovascular Disease (yes vs. } \\
\text { no) }\end{array}$ & 2.299 & $0.044^{*}$ & 9.968 & 1.061 \\
\hline Chronic Liver Disease (yes vs. no) & -0.72 & 0.465 & 0.487 & 0.071 \\
\hline \multicolumn{5}{|l|}{ Underlying Risk Factors } \\
\hline Hypotension (yes vs. no) & 1.935 & $0.036^{*}$ & 6.923 & 1.132 \\
\hline Sepsis/Septic Shock (yes vs. no) & 0.466 & 0.696 & 1.594 & 0.154 \\
\hline \multicolumn{5}{|l|}{ Laboratory Tests } \\
\hline Basal Blood Urea Level & 0.079 & $0.039^{*}$ & 1.083 & 1.004 \\
\hline Basal SCr Concentration & 1.404 & 0.168 & 4.072 & 0.553 \\
\hline SCr Concentration at Presentation & -0.032 & 0.926 & 0.968 & 0.493 \\
\hline Model Chi-square $(\mathrm{P})$ & \multicolumn{4}{|c|}{$5.834(0.666)$} \\
\hline Constant $(\mathrm{P})$ & \multicolumn{4}{|c|}{$-6.227(0.111)$} \\
\hline
\end{tabular}

Table 5: Multivariable logistic regression analysis for progression of AKI in critically ill patients.

\section{Discussion}

AKI is a frequent complication in patients admitted to the ICU and is associated with increased morbidity and mortality, increased length of hospital stay, cost, readmission, ventilator days and need for posthospitalization care [19]. International guidelines recommend risk assessment for AKI for the purpose of managing modifiable factors and preventing kidney injury progression and severity [20]. We chose to assess the risk of moderate to severe AKI rather than all AKI because this severity (corresponding to KDIGO stage 2 and 3 ) has been shown to be associated with a significantly increased incidence of clinically important outcomes such as need for renal replacement therapy, in hospital death and persistent renal dysfunction [21,22].

In this prospective cohort study, progression of AKI occurred in almost one third $(33.75 \%)$ of patients admitted to the medical ICU. Hypotension and sepsis were independently associated with progression of AKI. The use of nephrotoxic agents was excluded from all comparisons due to the very small size of the sample (only 10 patients (12.5\%) received nephrotoxic agents compared to 70 patients (87.5\%) who didn't). Our results confirmed the findings of many other 
studies that revealed significant associations with the same factors [23-27].

The association between different co-morbidities and progression of AKI varies widely across studies. While we found that progression was significantly associated with history of CKD, Raimundo et al. [27] revealed that progression is significantly associated with CVD. Kashani et al. [24] found a significant association with DM and HTN. Sileanu et al. [23] revealed that DM, CVD, CKD, HTN and increased BMI are all associated with the progression of AKI. These variations may reflect differences in baseline patient characteristics, criteria used to define $\mathrm{AKI}$ and AKI progression, study design and the type of ICUs.

We assessed the severity of illness on admission to the ICU using APACHE II and SOFA scores. We found that progressors had significantly higher APACHE II score, while no significant difference was found as regards the SOFA score. Raimundo et al. [27] postulated the same results.

Regarding patient outcomes, Koyner et al. [26] found that progression is significantly associated with RRT, ICU mortality and longer ICU stay. These findings are consistent with our results. In addition, we found that progressors had a significantly higher level of $\mathrm{SCr}$ at the time of discharge.

In our study, the results were similar between progressors and nonprogressors as regards age and sex. These results were in line with those revealed by Raimundo et al. [27], Poukkanen et al. [25] and Koyner et al. [26]. In contrast, Sileanu et al. [23] and Kashani et al. [24] found that increased age is associated with the progression of AKI. This could be attributed to the large size of the sample in the later studies and to the finding that both included patients with no AKI in the control group.

Compared to those who didn't receive RRT, we found that patients treated with RRT were more likely to have CKD, stage $3 \mathrm{AKI}$, had higher SCr and higher APACHE II score.

Regarding ICU mortality, we agreed with Raimundo et al. [27] and Peres et al. [28] that non-survivors had higher arterial lactate levels, higher blood urea and admission creatinine levels and higher APACHE II and SOFA scores. Patients with CKD, liver disease, progressors (to AKI stage 2 or 3 ) and those with sepsis or septic shock had an increased risk for death; the same findings demonstrated by Chertow et al. [29] and many other studies [28,30,31].

To the best of our knowledge, our study is the first to validate the usefulness of urinary netrin-1 as a predictor of AKI progression, the need for RRT and ICU mortality in adults with the usual confounding variables and comorbid conditions that normally accumulate with increasing age. We constructed ROC curves to assess this validity. Our results have shown that urinary netrin-1 level had no value in predicting any of the previously mentioned outcomes. This leads us to question its role and to recommend that more studies are needed to establish the role of netrin-1 in various forms and stages of AKI. Studies should also examine whether the role of netrin-1 can be improved by combining it with other biomarkers.

Our study has important limitations. First, we did not capture many processes of care variables (e.g., contrast use) or types of AKI (septic vs. non-septic AKI) that might have contributed to variation in risk and outcomes of AKI. Second, we did not estimate UO prior to ICU admission which could have underestimated the risk and outcomes of AKI. Third, we did not examine the interaction between UO and serum creatinine as patients with low UO (due to oliguria and fluid overload) might have had spuriously lower serum creatinine values biasing the severity of AKI. Fourth, this study attempted to identify the risk factors associated with disease progression. However, because we assume that the etiology is often multifactorial and that multiple risk factors could be present, the relative importance of each risk factor could not be identified. Finally, the reduced size of our patient population is another limitation.

\section{Conclusions}

AKI progression was more common among patients with history of CKD, hypotensive patients, septic patients, those who needed RRT and those who died. Cardiovascular disease, hypotension and higher basal blood urea level were independent risk factors for AKI progression. Urinary netrin-1 had no significant value as a predictor of disease progression, the need for RRT or ICU mortality.

\section{References}

1. Bellomo R, Kellum JA, Ronco C (2012) Acute kidney injury. Lancet 380: 756-766.

2. Halilovic J, Dager W (2016) Acute kidney injury in pharmacotherapy: A pathophysiologic approach (edn DiPiro JT et al.) 1898-1900.

3. Uchino S, Kellum JA, Bellomo R, Doig GS, Morimatsu H, et al. (2005) Acute renal failure in critically ill patients. JAMA 294: 813-818.

4. Case J, Khan S, Khalid R, Khan A (2013) Epidemiology of acute kidney injury in the intensive care unit. Crit Care Res Pract 2013: 1-9.

5. Legrand M, Dupuis C, Simon C, Gayat E, Mateo J, et al. (2013) Association between systemic hemodynamics and septic acute kidney injury in critically ill patients: A retrospective observational study. Crit Care 17: R278.

6. Seller-Pérez G, Más-Font S, Pérez-Calvo C, Villa-Díaz P, Celaya-López M, et al. (2016) Acute kidney injury: Renal disease in the ICU. Med Intensiva 40: 374-382.

7. Devarajan P (2007) Emerging biomarkers of acute kidney injury. Contrib Nephrol 156: 203-212.

8. Reeves WB, Kwon O, Ramesh G (2008) Netrin-1 and kidney injury. II. Netrin-1 is an early biomarker of acute kidney injury. Am J Physiol Renal Physiol 294: F731-F738.

9. Ramesh G, Krawczeski CD, Woo JG, Wang Y, Devarajan P (2010) Urinary netrin-1 is an early predictive biomarker of acute kidney injury after cardiac surgery. Clin J Am Soc Nephrol 5: 395-401.

10. Khwaja A (2012) KDIGO clinical practice guidelines for acute kidney injury. Nephron Clin Pract 120: 179-184.

11. Levy MM, Fink MP, Marshall JC, Abraham E, Angus D, et al. (2013) 2001 SCCM/ESICM/ACCP/ATS/SIS International sepsis definitions conference. Intensive Care Med 29: 530-538.

12. Naved SA, Siddiqui S, Khan FH (2011) APACHE-II score correlation with mortality and length of stay in an intensive care unit. J Coll Physicians Surg Pak 21: 4-8.

13. Ferreira FL, Bota DP, Bross A, MélotC, Vincent JL (2001) Serial evaluation of the SOFA score to predict outcome in critically ill patients. JAMA 286: 1754-1758.

14. Ramesh G, Kwon O, Ahn K (2010) Netrin-1: A novel universal biomarker of human kidney injury. Transplant Proc 42: 1519-1522.

15. Malhotra R, Kashani KB, Macedo E, Kim J, Bouchard J, et al. (2017) A risk prediction score for acute kidney injury in the intensive care unit. Nephrol Dial Transplant 32: 814-822.

16. Kane-Gill SL, Sileanu FE, Murugan R, Trietley GS, Handler SM, et al. (2015) Risk factors for acute kidney injury in older adults with critical Illness: A retrospective cohort study. Am. J. Kidney Dis 65: 860-869.

17. Wen C, Xue FS, Yang GZ, Liu YY (2017) Assessing incidence and risk factors of acute kidney injury in traumatic patients. Injury 48: 6-7. 
Citation: El Sharkawy A, El Wakil H, Naga Y, Younan D (2018) Assessment of Urinary Netrin-1 as a Marker for Progression of Acute Kidney Injury in Critically III Patients: Prospective Cohort Study. J Kidney 4: 164. doi:10.4172/2472-1220.1000164

Page 7 of 7

18. Trongtrakul K, Sawawiboon C, Wang AY, Chitsomkasem A, Limphunudom P, et al. (2017) Acute kidney injury in critically ill surgica patients: Epidemiology, risk factors and outcomes. Nephrology.

19. Horkan CM, Purtle SW, Mendu ML, Moromizato T, Gibbons FK, et al (2015) The association of acute kidney injury in the critically ill and postdischarge outcomes: A cohort study. Crit Care Med 43: 354-364.

20. Kellum JA (2012) Kidney disease: Improving global outcomes (KDIGO) acute kidney injury work group. KDIGO clinical practice guideline for acute kidney injury. Kidney Int Suppl 2: 124-138.

21. Murugan R, Subramanyam VK, Lee M, Yende S, Kong L, et al. (2010) Acute kidney injury in non-severe pneumonia is associated with an increased immune response and lower survival. Kidney Int 77: 527-535.

22. Hoste EAJ, Clermont G, Kersten A, Venkataraman R, Angus DC, et al (2006) RIFLE criteria for acute kidney injury are associated with hospital mortality in critically ill patients: A cohort analysis. Crit Care 10: 1-10.

23. Sileanu FE, Murugan R, Lucko N, Clermont G, Kane-Gill SL, et al. (2015) AKI in low-risk versus high-risk patients in intensive care. Clin J Am Soc Nephrol 10: 187-196.

24. Kashani K, Al-Khafaji A, Ardiles T, Artigas A, Bagshaw SM, et al. (2013) Discovery and validation of cell cycle arrest biomarkers in human acute kidney injury. Crit Care 17: 1-12.
25. Poukkanen M, Wilkman E, Vaara ST, Pettilä V, Kaukonen KM, et al. (2013) Hemodynamic variables and progression of acute kidney injury in critically ill patients with severe sepsis: Data from the prospective observational FINNAKI study. Crit Care 17: R295.

26. Koyner JL, Garg AX, Coca SG, Sint K, Thiessen-Philbrook H, et al. (2012) Biomarkers predict progression of acute kidney injury after cardiac surgery. J Am Soc Nephrol 23: 905-914.

27. Raimundo M, Crichton S, Syed Y, Martin JR, Beale R, et al. (2015) Low systemic oxygen delivery and BP and risk of progression of early AKI. Clin J Am Soc Nephrol 10: 1340-1349.

28. Peres LA, Wandeur V, Matsuo T (2015) Predictors of acute kidney injury and mortality in an intensive care unit. J Bras Nefrol 37: 38-46.

29. Chertow GM, Burdick E, Honour M, Bonventre JV, Bates DW (2005) Acute kidney injury, mortality, length of stay and costs in hospitalized patients. J Am Soc Nephrol 16: 3365-3370.

30. Selby NM, Kolhe NV, McIntyre CW, Monaghan J, Lawson N, et al. (2012) Defining the cause of death in hospitalised patients with acute kidney injury. PLoS One 7: 1-7.

31. Rewa O, Bagshaw SM (2014) Acute kidney injury-epidemiology, outcomes and economics. Nat Rev Nephrol 10: 193-207. 